\title{
Removal of cobalt(II) ion from aqueous solution by chitosan-montmorillonite
}

\author{
Hailin Wang ${ }^{1}$, Haoqing Tang ${ }^{2,3}$, Zhaotie Liu ${ }^{2,3}$, Xin Zhang ${ }^{1}$, \\ Zhengping $\mathrm{HaO}^{1}$, Zhongwen $\mathrm{Liu}^{2,3, *}$ \\ 1. Research Center for Eco-Environmental Sciences, Chinese Academy of Sciences, Beijing 100085, China. E-mail: wanghailin@cee.cn \\ 2. Key Laboratory of Applied Surface and Colloid Chemistry, Shanxi Normal University, Xi'an 710062, China \\ 3. School of Chemistry \& Chemical Engineering, Shanxi Normal University, Xi'an 710062, China
}

\section{A R T I C L E I N F O}

\section{Article history:}

Received 25 October 2013

Revised 19 March 2014

Accepted 3 April 2014

Available online 2 July 2014

Keywords:

Chitosan

Montmorillonite

$\mathrm{Co}^{2+}$

Isotherm

Kinetics

\begin{abstract}
A B S T R A C T
Montmorillonite (MMT) modified with chitosan (CTS, molecular weight $=5 \times 10^{4}$ ) was applied to remove heavy metal cations by using $\mathrm{Co}^{2+}$ as a model ion. An increase in MMT interlayer distance observed from X-ray diffraction indicates the intercalation of CTS into MMT. Together with the results of scanning electron microscopy and Fourier transform infrared spectroscopy, it was concluded that the composite material of CTS and MMT (CTSMMT) was prepared successfully. The mass ratio of CTS to MMT had a strong influence on the adsorption performance of CTS-MMT. The highest adsorption value of $150 \mathrm{mg} / \mathrm{g}$ was obtained over the composite material with CTS to MMT mass ratio of 0.25 , which is much higher than those reported in other studies. The adsorption isotherms and kinetic results indicated that $\mathrm{Co}^{2+}$ was adsorbed over CTS-MMT in a multilayer model, and the chemical sorption of $\mathrm{Co}^{2+}$ was determined to be the rate-limiting step.

(C) 2014 The Research Center for Eco-Environmental Sciences, Chinese Academy of Sciences. Published by Elsevier B.V.
\end{abstract}

\section{Introduction}

Treatment of industrial wastewater with heavy metal ions is a major issue and the development of effective adsorbents for removal of those metal ions is of great importance. Activated carbon has been widely studied and used for the removal of mercury, cadmium, lead, cobalt, copper and so on in terms of cost, simplicity of design and operation (Netzer and Hughes, 1984; Corapcioglu and Huang, 1987; Gomez-Serrano et al., 1998). However, high capital and regeneration cost limit its large scale application. Recent studies have focused on relatively low cost adsorbents such as zeolite, montmorillonite, kaolinitic clay, mineral silicates, sepiolite and others (Ali and El-Bishtawi, 1997; Orumwense, 1996; Sanchez et al., 1999; Brigatti et al., 2000; Green-Pederson et al., 1997). Chitosan (poly- $\beta$-(1,4)-2-amino-2-deoxy-glucopyranose, CTS) is a product of the deacetylation of chitin (Septhum et al., 2007), which is the second most abundant natural biopolymer on earth after cellulose. CTS is an excellent natural adsorbent in that its amine $\left(-\mathrm{NH}_{2}\right)$ and hydroxyl $(-\mathrm{OH})$ groups may serve as coordination sites to form complexes with various heavy metal ions. It can remove metal ions effectively by adsorptive enrichment. Compared with activated carbon, CTS is self degradative, non-toxic, low cost, and environmentally benign. Thus, it is widely used in many fields such as textiles, leather, food, bioengineering, agriculture, sewage treatment and so on. However, the poor selective adsorption, small surface area and low porosity of chitosan limit its application in pollutant adsorption (Ahmaruzzaman, 2008). Montmorillonite (MMT) is a 2:1 layered aluminosilicate of smectite-type clay, which is

* Corresponding author. E-mail: zwliu@snnu.edu.cn (Zhongwen Liu). 
composed of two tetrahedral sheets with $\mathrm{Si}$ in the cationic sites sandwiching an octahedral Al sheet. The partial substitution of $\mathrm{Al}^{3+}$ for the tetrahedral $\mathrm{Si}^{4+}$ and $\mathrm{Mg}^{2+}$ makes the layers negatively charged, which is neutralized by exchangeable cations in the interlayer space. Commonly, alkali or alkaline earth metal cations like $\mathrm{Na}^{+}, \mathrm{Ca}^{2+}$, etc., are in the interlayer of natural MMT. The porous structure, high surface area, capability of exchanging interlayer cations, and environmental compatibility make MMT one of the most promising candidates for decontamination and disposal of wastewater with highlevel heavy metal cation content (Bhattacharyya and Gupta, 2008).

It is hypothesized that the combination of CTS with MMT may create a more efficient adsorbent. Thus, in this work, we developed a simple method to prepare a composite of MMT and CTS, and $\mathrm{Co}^{2+}$ was selected as a typical heavy ion to test the adsorption with the aim of testing the removal efficiency of this new material.

\section{Materials and methods}

\subsection{Preparation of CTS-MMT}

CTS of $0.5 \mathrm{~g}$ with molecular weight $5 \times 10^{4}$ (>90\% degree of deacetylation, Golden-Shell Biochemical Co., Ltd., China) was dissolved in $50 \mathrm{~mL}, 5 \%(\mathrm{~V} / \mathrm{V}$ ) acetic acid (China Pharmaceutical Group Co., Ltd., China) to form a sol, and the sol was stirred at $60^{\circ} \mathrm{C}$ for $3 \mathrm{hr}$. After cooling to $30^{\circ} \mathrm{C}$, a certain content of MMT (Zhejiang Sanding Technology Co., Ltd., China) was added into the sol according to the designed mass ratio (CTS:MMT $=1$, $0.5,0.25,0.1,0.05)$ and stirred for $24 \mathrm{hr}$. After drying the solid in a vacuum oven at $70^{\circ} \mathrm{C}$, it was ground and sieved to 100 mesh particles that were then collected for adsorption studies.

\subsection{SEM, XRD and FT-IR characterization}

Scanning electron microscope (SEM) observations were carried out (Quanta 200 Philips, USA). X-Ray diffraction patterns (XRD) were recorded in the range of $2-40^{\circ}(2 \theta)$ with a diffractometer (D/max $2550 \mathrm{VB}+/ \mathrm{PC}$ Rigaku, Japan) using $\mathrm{Cu}$ $\mathrm{K} \alpha$ radiation $(\lambda=0.154 \mathrm{~nm})$. The applied voltage and current were $30 \mathrm{kV}$ and $40 \mathrm{~mA}$, respectively. Fourier transform infrared spectroscopy (FT-IR) was also performed using a spectrometer (Avatar 360 Nicolet, USA). FT-IR spectra in the transmittance mode were recorded in the range of 500$4000 \mathrm{~cm}^{-1}$ at a resolution of $4 \mathrm{~cm}^{-1}$.

\section{3. $\mathrm{Co}^{2+}$ adsorption tests}

$\mathrm{Co}^{2+}$ adsorption experiments were carried out by adding $0.1 \mathrm{~g}$ CTS-MMT into $25 \mathrm{~mL}, 8.25 \times 10^{-4} \mathrm{~g} / \mathrm{mL} \mathrm{Co}\left(\mathrm{NO}_{3}\right)_{2}$ (China Pharmaceutical Group Co., Ltd., China) solution at $30^{\circ} \mathrm{C}$ for $1,2,4,8$, 12 and $24 \mathrm{hr}$, respectively. The slurry after adsorption was filtered and centrifuged. The concentration of $\mathrm{Co}^{2+}$ in the solution was measured with an atomic adsorption spectrophotometer (AAS, Beijing Purkinje, China), and the interaction of $\mathrm{Co}^{2+}$ with the adsorbent was studied using a UV-Vis diffuse reflectance spectrophotometer (UV-3000, Hitachi, Japan), and thermodynamic and kinetic studies of $\mathrm{Co}^{2+}$ adsorption were also carried out.

\section{Results and discussion}

\subsection{Properties of CTS, MMT and CTS-MMT}

SEM micrographs of CTS, MMT and CTS-MMT are shown in Fig. 1. CTS displays an irregular particulate morphology having smooth surfaces. The MMT is composed of flakes or agglomerated flakes with varied sizes. In the case of CTSMMT, larger seemingly gelled particles with small flakes and rough surfaces were observed.

The XRD patterns of CTS, MMT and CTS-MMT are given in Fig. 2. From the characteristic (001) diffraction, structural changes of the MMT are clearly observed. The (001) diffraction peak of MMT occurred at $2 \theta$ of $7.545^{\circ}$, corresponding to a d001 spacing of $1.1707 \mathrm{~nm}$. However, the d001 spacing of CTS-MMT was slightly increased to $1.3497 \mathrm{~nm}\left(2 \theta=6.543^{\circ}\right)$, indicating that the MMT interlayer expanded, which can be reasonably ascribed to the intercalation of CTS into the MMT interlayer region, leading to the formation of CTS-MMT.

The FT-IR spectra of CTS, MMT and CTS-MMT are shown in Fig. 3. The IR spectra of CTS exhibit an -OH stretching vibration at around $3400 \mathrm{~cm}^{-1},-\mathrm{CH}$ stretching vibration at $2932 \mathrm{~cm}^{-1}$, and $-\mathrm{NH}$ bending vibration at $1650 \mathrm{~cm}^{-1}$, respectively. The $-\mathrm{CH}_{2}$ bending vibration observed at $1451 \mathrm{~cm}^{-1}$ and the peaks at 1018 and $1110 \mathrm{~cm}^{-1}$ belong to the $-\mathrm{CO}$ stretching vibration in the $-\mathrm{COH}$ group. The shoulder IR adsorption at $3625 \mathrm{~cm}^{-1}$ originates from the stretching of hydroxyl groups coordinated to octahedral cations. The 3442 and $1639 \mathrm{~cm}^{-1}$ bands for MMT are assigned to stretching and bending vibrations of hydroxyl groups in molecular water present in MMT. The most intense peak at $1040 \mathrm{~cm}^{-1}$ derives from the stretching vibration of $\mathrm{Si}-\mathrm{O}$ in the tetrahedral sheet. In comparison with the spectra of CTS and MMT, two characteristics of CTS-MMT are observed, one is that an intense new peak and a small new peak appear at $2355 \mathrm{~cm}^{-1}$ and $1554 \mathrm{~cm}^{-1}$, the other is that $-\mathrm{OH},-\mathrm{NH}$, and $-\mathrm{CH}$ group positions clearly shifted. These changes indicate that strong interactions are present in CTS-MMT.

\subsection{Adsorption behavior}

Fig. 4 shows the adsorption results of $\mathrm{Co}^{2+}$ on CTS-MMT for different times $(1,2,4,8,12$ and $24 \mathrm{hr})$. It was found that the adsorption amounts for these CTS-MMT materials increased quickly in $4 \mathrm{hr}$ and then became slow and reached the maximum value at $12 \mathrm{hr}$. CTS-MMT with a mass ratio of 0.25 showed the highest adsorption amount $(150 \mathrm{mg} / \mathrm{g})$ at $12 \mathrm{hr}$. The adsorption potential of CTS-MMT for cobalt in this study was compared with that of other reported adsorbents as summarized in Table 1 (Manohar et al., 2006; Yavuz et al., 2003; Parab et al., 2006; Anoop Krishnan and Anirudhan, 2008; Ahmadpour et al., 2009; Suhasini et al., 1999; Erdem et al., 2004; Smiciklas et al., 2006; Repo et al., 2009; Bhatnagar et al., 2010). It can be seen that the prepared adsorbent in this study shows good performance for cobalt removal, which might be related to the combination of the advantages of both CTS and MMT.

As mentioned above, CTS is known as a good adsorbent due to its abundant amine $\left(-\mathrm{NH}_{2}\right)$ and hydroxyl $(-\mathrm{OH})$ 

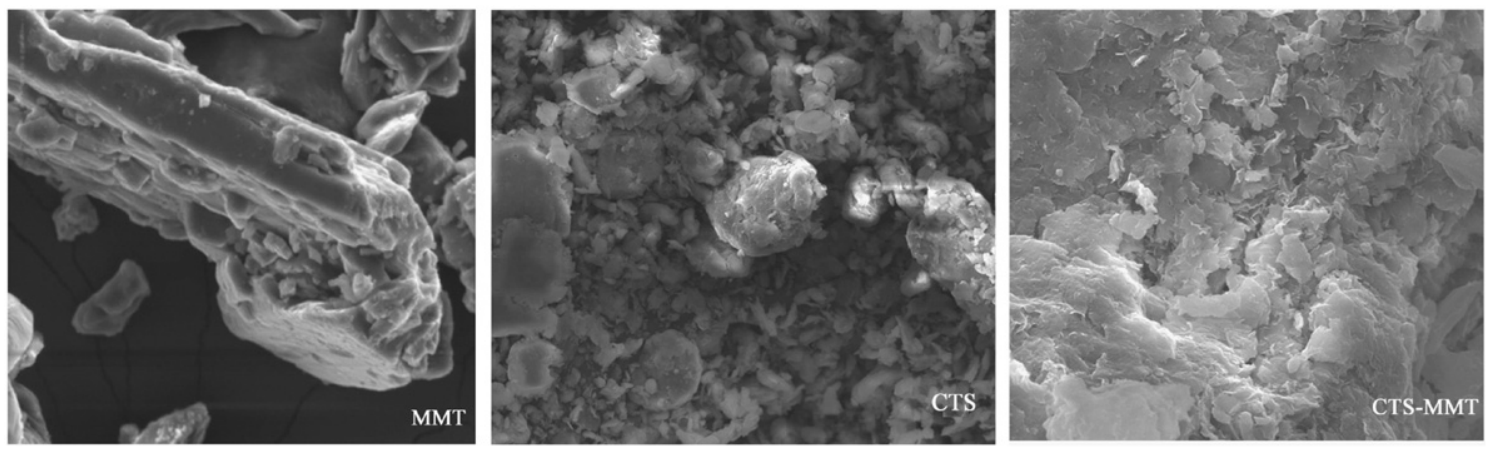

Fig. 1 - SEM images of MMT, CTS, and CTS-MMT.

groups, which can form complexes with various heavy metal ions. Here, the prepared CTS-MMT maintains the adsorption characteristics of CTS, and $-\mathrm{OH}$ and $-\mathrm{NH}$ groups are also observed via FT-IR, which might serve as coordination sites to form complexes with $\mathrm{Co}^{2+}$. The UV-Vis diffuse reflectance spectra of $\mathrm{Co}^{2+}$-absorbed CST-MMT are shown in Fig. 5. It can be observed clearly that the spectrum is dominated by two peaks occurring at $250 \mathrm{~nm}$ and $300-600 \mathrm{~nm}$, respectively. The narrow peak at $250 \mathrm{~nm}$ can be attributed to the absorption of CST-MMT. Meanwhile, the broad peak occurring at 300-600 nm is characteristic of $\mathrm{Co}^{2+}$ (Zhang et al., 2011). Furthermore, no peak attributable to $\mathrm{Co}^{3+}$ is detected. Thus, the removal of $\mathrm{Co}^{2+}$ is carried out by the formation of $\mathrm{Co}^{2+}$ complexes, and the adsorption is a chemical adsorption process.

Langmuir, Freundlich and Temkin isotherms are widely used to describe the adsorption characteristics of adsorbents. Important information about adsorbent surface properties can be known from the adsorption isotherms (Liu et al., 2011; Juang and Shao, 2002), and the linear form of Langmuir, Freundlich and Temkin isotherms can be written as Eqs. (1)(3), respectively.

$$
\frac{C_{\mathrm{e}}}{Q_{\mathrm{e}}}=\frac{1}{B Q_{\mathrm{m}}}+\frac{C_{\mathrm{e}}}{Q_{\mathrm{m}}}
$$

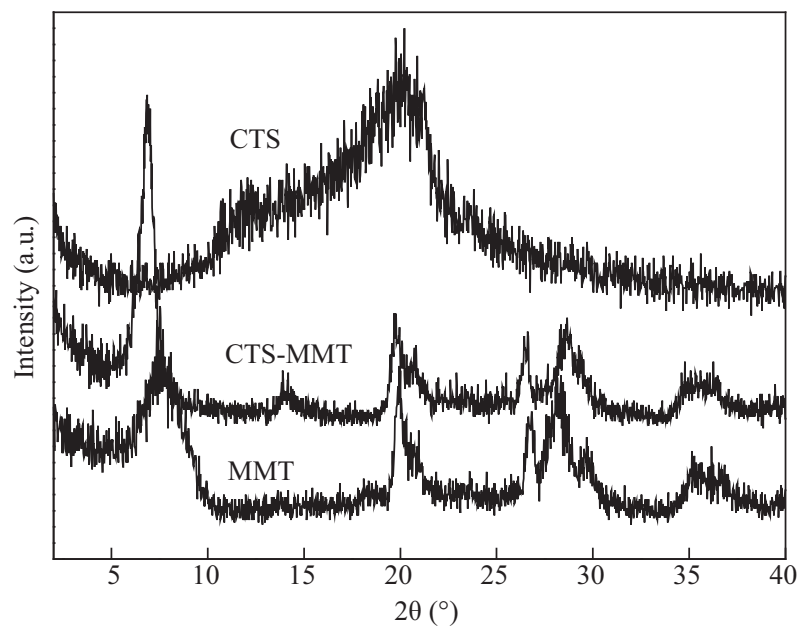

Fig. 2 - XRD patterns of MMT, CTS, and CTS-MMT. $\log Q_{\mathrm{e}}=\log K+\frac{1}{n} \log C_{\mathrm{e}}$

$Q_{\mathrm{e}}=A+B \log C_{\mathrm{e}}$

where, $C_{e}(g / L)$ is the equilibrium concentration of $\mathrm{Co}^{2+}$ in solution, $Q_{e}(\mathrm{mmol} / \mathrm{g})$ is the amount adsorbed per unit mass of absorbent, $Q_{m}(\mathrm{mmol} / \mathrm{g})$ is the maximum sorption capacity, and $B, K, n$, and $A$ are adsorption constants. The correlation coefficients based on the three isotherms are summarized in Table 2. Independent of the adsorbents, the Temkin equation gave the best fit for all the results, indicating multilayer adsorption of $\mathrm{Co}^{2+}$ on adsorption sites having different energies.

The efficiency of an adsorbent for the removal of metal cations is essentially determined by adsorption kinetics. In order to determine the controlling steps such as mass transfer and chemical reaction, different kinetic models are used to fit the experimental data (Annadurai et al., 2008; Zhou et al., 2009). The linear form of the pseudo first-order kinetic model, pseudo second-order kinetic model, and intraparticle diffusion kinetic model can be written as follows, respectively.

$\frac{1}{q_{t}}=\frac{k_{1}}{q_{\mathrm{e}} t}+\frac{1}{q_{\mathrm{e}}}$

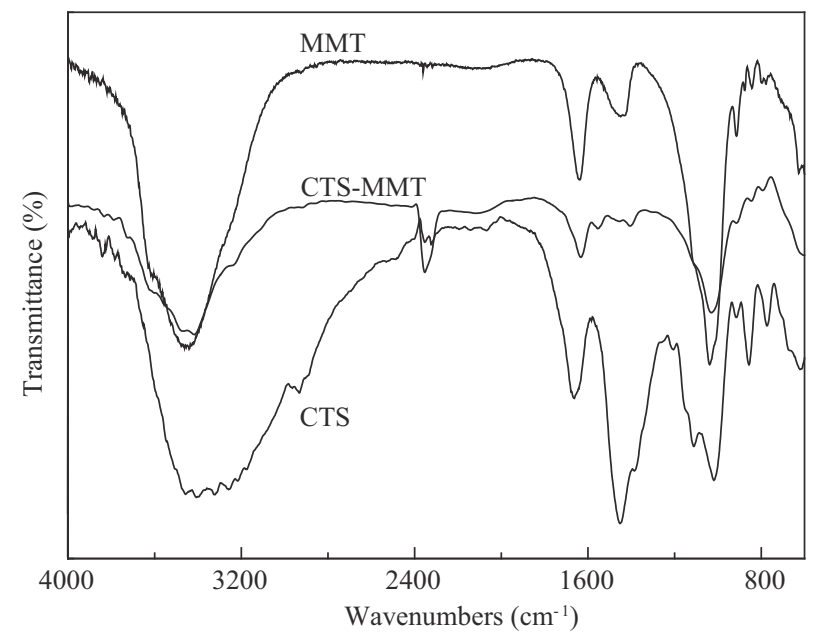

Fig. 3 - FT-IR spectra of CTS, MMT, and CTS-MMT. 


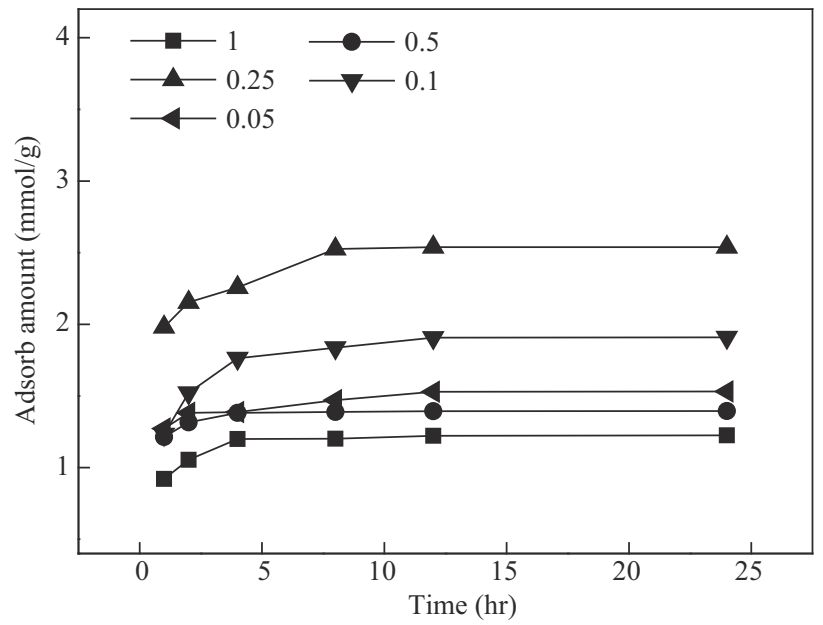

Fig. 4 - Adsorption of $\mathrm{Co}^{2+}$ on the CTS-MMT with different mass ratios.

$\frac{t}{q_{t}}=\frac{1}{k_{2} q_{\mathrm{e}}{ }^{2}}+\left(\frac{1}{q_{\mathrm{e}}}\right) t$

$q_{t}=k_{\mathrm{i}} t^{\frac{1}{2}}+c$

where, $q_{t}(\mathrm{mg} / \mathrm{g})$ is the amount of $\mathrm{Co}^{2+}$ at time $\mathrm{t}(\mathrm{min}), q_{\mathrm{e}}(\mathrm{mg} / \mathrm{g})$ is the equilibrium adsorption capacity, and $k_{1}\left(\min ^{-1}\right), k_{2}$ $(\mathrm{g} /(\mathrm{mg} \cdot \mathrm{min}))$ and $k_{\mathrm{i}}\left(\mathrm{mg} /\left(\mathrm{g} \cdot \mathrm{min}^{0.5}\right)\right)$ are the rate constants of the pseudo first-order kinetic model, pseudo second-order kinetic model and intraparticle diffusion kinetic model, respectively. According to the three kinetic models, the correlation coefficients are listed in Table 3. The adsorption of $\mathrm{Co}^{2+}$ on CTS-MMT best fits the pseudo second-order equation, indicating that chemical sorption is the rate-limiting step.

The calculated values of free energy change $(\Delta G)$, enthalpy change $(\Delta H)$, and entropy change $(\Delta S)$ are given in Table 4 . They were calculated using the following equations.

$K_{\mathrm{c}}=\frac{C_{\mathrm{A}}}{C_{\mathrm{s}}}$
$\Delta G^{\theta}=-R T \ln K_{\mathrm{c}}$

$\ln K_{\mathrm{c}}=\frac{\Delta S^{\theta}}{R}-\frac{\Delta H^{\theta}}{R T}$

where, $K_{C}$ is the equilibrium constant, $C_{A}(g)$ is the amount of $\mathrm{Co}^{2+}$ adsorbed in per unit mass of absorbent at equilibrium, $C_{\mathrm{S}}$ $(\mathrm{g} / \mathrm{L})$ is the equilibrium concentration of the $\mathrm{Co}^{2+}$ in solution, $\Delta G^{\theta}(\mathrm{kJ} / \mathrm{mol})$ is the adsorption free energy change, $\Delta H^{\theta}(\mathrm{kJ} / \mathrm{mol})$ is the enthalpy change, $\Delta S^{\theta}(\mathrm{J} /(\mathrm{K} \cdot \mathrm{mol}))$ is the entropy change, $R$ $(\mathrm{kJ} /(\mathrm{K} \cdot \mathrm{mol}))$ is the gas constant, and $\mathrm{T}(\mathrm{K})$ is the absolute temperature. The values of enthalpy $\left(\Delta H^{\theta}\right)$ and entropy $\left(\Delta S^{\theta}\right)$ were obtained from the slope and intercept of $\ln K_{\mathrm{c}}$ vs $1 / \mathrm{T}$ plots.

The calculated values of free $\Delta G, \Delta H$ and $\Delta S$ were obtained according to the methods in other studies (Septhum et al., 2007; Choudhari and Kariduraganavar, 2009). The value of $\Delta H^{\theta}$ is positive $(14.00 \mathrm{~kJ} / \mathrm{mol})$, suggesting that the adsorption of $\mathrm{Co}^{2+}$ is endothermic. The value of $\Delta G^{\theta}(-1.66 \mathrm{~kJ} / \mathrm{mol})$ is negative, indicating that the reaction is spontaneous at $30^{\circ} \mathrm{C}$. The positive value of $\Delta S^{\theta}(51.67 \mathrm{~J} /(\mathrm{mol} \cdot \mathrm{K}))$ shows that particles in equilibrium solution decrease randomness compared to the initial solution. Before adsorption, there were only metal ions and water molecules, but metal ions were combined with water molecules, forming aquo-metal ions. When adsorption equilibrium was reached, some metal ions in the solution were absorbed by CTS, and water molecules were released from the aquo-metal ions, thus the total particles in equilibrium solution increased.

\section{Conclusions}

A simple method was developed to prepare CTS-MMT composites, whose formation was confirmed by XRD and FT-IR results. Greatly enhanced adsorption of $\mathrm{Co}^{2+}$ was achieved on CTS-MMT in comparison with CTS or MMT alone, and was dependent on the specific experimental conditions and the molecular weight of CTS. Irrespective of the initial concentration of $\mathrm{Co}^{2+}$, CTS-MMT with mass ratio 0.25 (CTS:MMT) showed better performance for $\mathrm{Co}^{2+}$

Table 1 - Comparison of $\mathrm{Co}^{2+}$ adsorption over different adsorbents.

\begin{tabular}{lrcccl} 
Adsorbent & $\begin{array}{c}\mathrm{Co}^{2+} \\
(\mathrm{mg} / \mathrm{L})\end{array}$ & Adsorbent dose & $\begin{array}{c}\text { Reaction time } \\
(\mathrm{hr})\end{array}$ & $\begin{array}{c}\text { Adsorption capacity } \\
(\mathrm{mg} / \mathrm{g})\end{array}$ & Reference \\
\hline Clay & 25 & $2.0 \mathrm{~g} / \mathrm{L}$ & 24 & 38.6 & Manohar et al. (2006) \\
Kaolinite & 2400 & $1.0 \mathrm{~g} / \mathrm{L}$ & 2 & 0.9 & Yavuz et al. (2003) \\
Coir pith & 50 & $2.0 \mathrm{~g} / \mathrm{L}$ & 2 & 12.8 & Parab et al. (2006) \\
Activated carbon & 1000 & $2.0 \mathrm{~g} / \mathrm{L}$ & 4 & 153.6 & Anoop Krishnan and Anirudhan (2008) \\
Almond green hull & 50 & $5.0 \mathrm{~g} / \mathrm{L}$ & 0.1 & 45.5 & Ahmadpour et al. (2009) \\
Biosorbent & 500 & $2.0 \mathrm{~g} / \mathrm{L}$ & 24 & 190.0 & Suhasini et al. (1999) \\
Zeolites & 400 & $20 \mathrm{~g} / \mathrm{L}$ & 5.5 & 14.4 & Erdem et al. (2004) \\
Hydroxyapatite & $5-1000$ & - & 24 & 20.9 & Smiciklas et al. (2006) \\
Silica gel & 400 & $2.0 \mathrm{~g} / \mathrm{L}$ & 4 & 20 & Repo et al. (2009) \\
Lemon peel & 1000 & $10 \mathrm{~g} / \mathrm{L}$ & 10 & 22 & Bhatnagar et al. (2010) \\
CTS-MMT & 825 & $4 \mathrm{~g} / \mathrm{L}$ & 12 & 150 & This study \\
\hline -: not mentioned. & \multicolumn{5}{c}{} \\
\hline
\end{tabular}




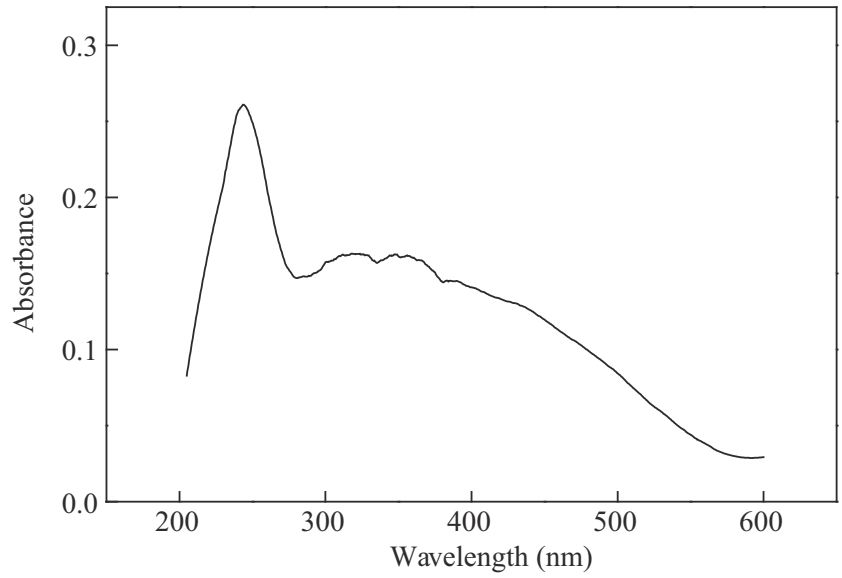

Fig. 5 - UV-Vis pattern of $\mathrm{Co}^{2+}$ absorbed CTS-MMT.

\begin{tabular}{|c|c|c|c|c|c|c|c|c|c|}
\hline \multirow[t]{2}{*}{ Mass ratio } & \multicolumn{4}{|c|}{ Langmuir } & \multicolumn{3}{|c|}{ Frenudlich } & \multicolumn{2}{|c|}{ Temkin } \\
\hline & $\mathrm{Q}_{\mathrm{m}}$ & $B$ & $R^{2}$ & $1 / n$ & $k$ & $R^{2}$ & A & $B$ & $R^{2}$ \\
\hline 1 & $1.91 \times 10^{-3}$ & -2.53 & 0.9945 & -2.26 & $1.77 \times 10^{-3}$ & 0.9972 & $-1.7 \times 10^{-3}$ & -0.033 & 0.9998 \\
\hline 0.5 & $2.84 \times 10^{-3}$ & -3.08 & 0.9986 & -2.91 & $1.90 \times 10^{-3}$ & 0.7942 & $-8.5 \times 10^{-4}$ & -0.029 & 0.9999 \\
\hline 0.25 & $8.64 \times 10^{-3}$ & -10.24 & 0.9946 & -0.53 & $6.88 \times 10^{-3}$ & 0.9905 & $4.5 \times 10^{-3}$ & -0.016 & 0.9962 \\
\hline 0.1 & $4.00 \times 10^{-3}$ & -4.05 & 0.9842 & -1.22 & $3.44 \times 10^{-3}$ & 0.9870 & $3.14 \times 10^{-4}$ & -0.026 & 0.9974 \\
\hline 0.05 & $3.30 \times 10^{-3}$ & -3.39 & 0.9958 & -1.49 & $2.88 \times 10^{-3}$ & 0.9972 & $-4.28 \times 10^{-4}$ & -0.028 & 0.9996 \\
\hline
\end{tabular}

Table 3 - Correlation coefficients $\left(R^{2}\right)$ of $\mathrm{Co}^{2+}$ adsorption by CTS-MMT.

\begin{tabular}{lccc}
$\begin{array}{c}\text { Mass } \\
\text { ratio }\end{array}$ & $\begin{array}{c}\text { Pseudo } \\
\text { first-order }\end{array}$ & $\begin{array}{c}\text { Pseudo } \\
\text { second-order }\end{array}$ & $\begin{array}{c}\text { Intraparticle } \\
\text { diffusion }\end{array}$ \\
\hline 1 & 0.8172 & 0.9966 & 0.8156 \\
0.5 & 0.6476 & 0.9997 & 0.7768 \\
0.25 & 0.2867 & 0.9935 & 0.8246 \\
0.1 & 0.6228 & 0.9918 & 0.864 \\
0.05 & 0.3912 & 0.9918 & 0.9226 \\
\hline
\end{tabular}

adsorption than other samples, and the maximum value was $150 \mathrm{mg} / \mathrm{g}$. The adsorption isotherms of $\mathrm{Co}^{2+}$ on the composites were best fitted by the Temkin equation, indicating multilayer adsorption of $\mathrm{Co}^{2+}$. Kinetics study revealed that the adsorption of $\mathrm{Co}^{2+}$ on CTS-MMT followed the pseudo second-order equation, indicating that chemical sorption is the rate-limiting step. Thermodynamic parameters such as $\Delta G^{\theta}, \Delta H^{\theta}$, and $\Delta S^{\theta}$ were also evaluated to understand the nature of sorption.

\section{Table 4 - Thermodynamic parameters.}

\begin{tabular}{llllll}
$\begin{array}{c}\text { Metal } \\
\text { ions }\end{array}$ & $\mathrm{T}\left({ }^{\circ} \mathrm{C}\right)$ & $\ln K_{\mathrm{c}}$ & $\begin{array}{c}\Delta \mathrm{G}^{\theta} \\
(\mathrm{kJ} / \mathrm{mol})\end{array}$ & $\begin{array}{c}\Delta \mathrm{S}^{\theta} \\
(\mathrm{J} /(\mathrm{mol} \cdot \mathrm{K}))\end{array}$ & $\begin{array}{c}\Delta H^{\theta} \\
(\mathrm{kJ} / \mathrm{mol})\end{array}$ \\
\hline $\mathrm{Co}^{2+}$ & 30 & 0.68 & -1.66 & 51.67 & 14.00 \\
& 60 & 1.12 & -3.10 & $/$ & $/$ \\
& 90 & 1.61 & -4.86 & $/$ & $/$ \\
\hline
\end{tabular}

As discussed above, the adsorption of $\mathrm{Co}^{2+}$ over CTS-MMT is a chemical process due to the formation of $\mathrm{Co}^{2+}$ complexes with amine $\left(-\mathrm{NH}_{2}\right)$ and hydroxyl $(-\mathrm{OH})$ groups and the parameters $\Delta G^{\theta}$ and $\Delta S^{\theta}$ also suggest that the process is spontaneous and irreversible. Thus, the regeneration of this synthesized material is difficult using common methods such as washing, calcination and others. Considering the low cost of CTS-MMT and the highly enriched $\mathrm{Co}^{2+}$ content of spent adsorbent, centralized disposal with other treatments to recycle Co-related materials might be a more economical option than regeneration.

\section{Acknowledgments}

This work was supported by the Fundamental Research Funds for the Central Universities (No. GK201002043).

\section{R E F E R E N C E S}

Ahmadpour, A., Tahmasbi, M., Bastami, T.R., Besharati, J.A., 2009. Rapid removal of cobalt ion from aqueous solutions by almond green hull. J. Hazard. Mater. 166 (2-3), 925-930.

Ahmaruzzaman, M., 2008. Adsorption of phenolic compounds on low-cost adsorbents: a review. Adv. Colloid Interf. Sci. 143 (1-2), 48-67.

Ali, A.A., El-Bishtawi, R., 1997. Removal of lead and nickel ions using zeolite tuff. J. Chem. Technol. Biotechnol. 69 (1), $27-34$. 
Annadurai, G., Ling, L.Y., Lee, J.F., 2008. Adsorption of reactive dye from an aqueous solution by chitosan: isotherm, kinetic and thermodynamic analysis. J. Hazard. Mater. 152 (1), 337-346.

Anoop Krishnan, K., Anirudhan, T.S., 2008. Kinetic and equilibrium modelling of cobalt(II) adsorption onto bagasse pith based sulphurised activated carbon. Chem. Eng. J. 137 (1), 257-264.

Bhatnagar, A., Minocha, A.K., Sillanpää, M., 2010. Adsorption removal of cobalt from aqueous solution by utilizing lemon peel as biosorbent. Biochem. Eng. J. 48 (2), 181-186.

Bhattacharyya, K.G., Gupta, S.S., 2008. Adsorption of a few heavy metals on natural and modified kaolinite and montmorillonite: a review. Adv. Colloid Interf. Sci. 140 (2), 114-131.

Brigatti, M.F., Lugli, C., Poppi, L., 2000. Kinetics of heavy-metal removal and recovery in sepiolite. Appl. Clay Sci. 16 (1-2), 45-57.

Choudhari, S.K., Kariduraganavar, M.Y., 2009. Development of novel composite membranes using quaternized chitosan and $\mathrm{Na}^{+}-\mathrm{MMT}$ clay for the pervaporation dehydration of isopropanol. J. Colloid Interface Sci. 338 (1), 111-120.

Corapcioglu, M.O., Huang, C.P., 1987. The adsorption of heavy metals onto hydrous activated carbon. Water Res. 21 (9), 1031-1144.

Erdem, E., Karapinar, N., Donat, R., 2004. The removal of heavy metal cations by natural zeolites. J. Colloid Interface Sci. 280 (2), 309-314.

Gomez-Serrano, V., Macias-Gorcia, A., Espinosa-Mansilla, A., Valenzuela-Calahorro, C., 1998. Adsorption of mercury, cadmium and lead from aqueous solution on heated treated and sulphurized activated carbon. Water Res. 32 (1), $1-4$.

Green-Pederson, H., Jenson, B.T., Pinol, N., 1997. Nickel adsorption on $\mathrm{MnO}_{2}, \mathrm{Fe}(\mathrm{OH})_{3}$, montmorillonite, humic acid and calcite: a comparative study. Environ. Technol. 18 (8), 807-815.

Juang, R.S., Shao, H.J., 2002. A simplified equilibrium model for sorption of heavy metal ions from aqueous solutions on chitosan. Water Res. 36 (12), 2999-3008.

Liu, H.J., Yang, F., Zheng, Y.M., Kang, J., Qu, J.H., Chen, J.P., 2011. Improvement of metal adsorption onto chitosan/sargassum sp. composite sorbent by an innovative ion-imprint technology. Water Res. 45 (1), 145-154.

Manohar, D.M., Noeline, B.F., Anirudhan, T.S., 2006. Adsorption performance of Alpillared bentonite clay for the removal of cobalt(II) from aqueous phase. Appl. Clay Sci. 31 (3-4), 194-206.

Netzer, A., Hughes, D.E., 1984. Adsorption of copper, lead and cobalt by activated carbon. Water Res. 18 (8), 927-933.

Orumwense, F.F.O., 1996. Removal of lead from water by adsorption on a kaolinitic clay. J. Chem. Technol. Biotechnol. 65 (4), 363-369.

Parab, H., Joshi, S., Shenoy, N., Lali, A., Sarma, U.S., Sudersanan, M., 2006. Determination of kinetic and equilibrium parameters of the batch adsorption of $\mathrm{Co}(\mathrm{II}), \mathrm{Cr}$ (III) and $\mathrm{Ni}$ (II) onto coir pith. Process Biochem. 41 (3), 609-615.

Repo, E., Kurniawan, T.A., Warchol, J.K., Sillanpää, M.E., 2009. Removal of Co(II) and Ni(II) ions from contaminated water using silica gel functionalized with EDTA and/or DTPA as chelating agents. J. Hazard. Mater. 171 (1-3), 1071-1080.

Sanchez, A.G., Ayuso, E.A., De, Blas.O.J., 1999. Sorption of heavy metals from industrial wastewater by low-cost mineral silicates. Clay Miner. 34 (3), 469-477.

Septhum, C., Rattanaphani, S., Bremner, J.B., Rattanaphai, V., 2007. An adsorption study of $\mathrm{Al}$ (III) ions onto chitosan. J. Hazard. Mater. 148 (1-2), 185-191.

Smiciklas, I., Dimović, S., Plećaš, I., Mitrić, M., 2006. Removal of $\mathrm{Co}^{2+}$ from aqueous solutions by hydroxyapatite. Water Res. 40 (12), 2267-2274.

Suhasini, I.P., Sriram, G., Asolekar, S.R., Sureshkumar, G.K., 1999. Biosorptive removal and recovery of cobalt from aqueous systems. Process Biochem. 34 (3), 239-247.

Yavuz, ö, Altunkaynak, Y., Güzel, F., 2003. Removal of copper, nickel, cobalt and manganese from aqueous solution by kaolinite. Water Res. 37 (4), 948-952.

Zhang, X.Y., Shen, Q., He, C., Wang, Y.F., Cheng, J., Hao, Z.P., 2011. CoMOR zeolite catalyst prepared by buffered ion exchange for effective decomposition of nitrous oxide. J. Hazard. Mater. 192 (3), 1756-1765.

Zhou, L., Wang, Y., Liu, Z., Huang, Q., 2009. Characteristics of equilibrium, kinetics studies for adsorption of $\mathrm{Hg}(\mathrm{II}), \mathrm{Cu}$ (II), and $\mathrm{Ni}(\mathrm{II})$ ions by thiourea-modified magnetic chitosan microspheres. J. Hazard. Mater. 161 (2-3), 995-1002. 